\title{
Container Volume Affects Growth and Development of Wax-apple
}

\author{
Y.M. Hsu' ${ }^{1}$ M.J. Tseng ${ }^{2}$, and C.H. Lin ${ }^{3}$ \\ National Chung Hsing University, Taichung, Taiwan 40227, Republic of \\ China
}

Additional index words. Syzygium samarangense, forcing culture, root restriction, shoot : root ratio

\begin{abstract}
The wax-apple [Syzygium samarangense (B1.) Merr. \& Perry] is a vigorous tropical fruit tree species that has five to six growth flushes per year. One-year-old, rootbearing wax-apple trees were grown in different-sized containers filled with potting mixture to test if container volume restricts shoot and/or root growth and thereby lends itself to forcing culture. The trunk cross-sectional area (TCSA) at $15 \mathrm{~cm}$ above the soil was measured to assess vegetative growth. After 6 months, the TCSA had increased quadratically with container volume. At the end of the first and second year, leaf count, leaf area, leaf dry mass, stem dry mass, shoot dry mass, and root dry mass were positively correlated with container volume. However, the shoot : root ratios remained fairly constant among treatments during the experimental period. Thus, root restriction is an effective means of reducing shoot and root growth of the wax-apple.
\end{abstract}

Growth of tropical and subtropical evergreen fruit trees occurs in cycles of vigorous vegetative growth followed by periods of low vegetative growth, during which time flowers are often initiated. Therefore, controlling the vigor of shoots is one of the main concerns for maintaining high and consistent yields. Although vegetative growth can be controlled by withholding water and nutrients (Proebsting et al., 1989; Richards, 1986), in practice, controlling the water supply may not always be manageable due to the high incidence of rainfall in tropical and subtropical regions.

Manipulating vegetative growth by training, pruning, and girdling (Ferhandez-Escobar et al., 1987), or by applying growth regulators (Tukey, 1981; Wood, 1984), also were used to control shoot growth. Alternating root and shoot growth cycles occur in many deciduous temperate zone fruit trees (Bevington and Castle, 1985; Head, 1968, 1969; Williamson and Coston, 1989). Root systems have been manipulated by root pruning (Geisler and Ferree, 1984a; Schupp and Ferree, 1987, 1988) and root restriction (Richards, 1986 Williamson and Coston, 1990) to control the shoot growth. Root pruning of woody plants only had a temporary effect on shoot growth (Geisler and Ferree, 1984b; Richards and Rowe, 1977a), but root restriction by limiting

Received for publication 6 Sept. 1995. Accepted for publication 29 June 1996. This work was supported by grant NSC 84-2311-B-005-015 B01 and the Council of Agriculture, Republic of China. The cost of publishing this paper was defrayed in part by the payment of page charges. Under postal regulations, this paper therefore must be hereby marked advertisement solely to indicate this fact.

${ }^{1}$ Department of Botany. Current address: Kaohsiung District Agricultural Improvement Station, 1 Longshu Lane, Mingshen Road, Pingtung, Taiwan, Republic of China.

${ }^{2}$ Department of Horticulture

${ }^{3}$ Department of Botany. the soil volume was capable of indefinitely dwarfing plants and controlling vegetative vigor (Carmi and Heuer, 1981; Richards, 1986; Richards and Rowe, 1977a). Therefore, even in a high-density peach [Prunus persica (L.) Batsch.] planting, root restriction by fabriclined trenches was still an effective means of controlling tree size (Williamson and Coston, 1990; Williamson et al., 1992). Information on the effects of root restriction on vigorous tropical fruit trees is very limited.

In Taiwan, several systems of inducing dormancy and budbreak, known as forcing culture, have been devised to produce offseason crops in several fruit trees (Lin et al., 1983, 1989). Under ordinary cultural practice, the harvest period of wax-apple in Taiwan extends from March to July. This period coincides with the monsoon rain and high temperatures that often cause inferior fruit quality. Thus, cultural systems involving withholding water, flooding, girdling, root pruning, etc., had been adapted to regulate flowering and harvesting period of wax-apple from January to May (Shu et al., 1990). By applying some of these treatments to the root system, vegetation can be reduced and the reproductive phase promoted. Therefore, in this study, the effects of root restriction on the growth and development of wax-apple shoots were evaluated by terms. use of various container volumes to potentially alter the fruiting season.

\section{Materials and Methods}

This experiment was conducted from 1991 until 1993 at the Kaohsiung District Agricultural Improvement Station (lat. $22^{\circ}$ ), Pintung, Taiwan. One-year-old, root-bearing wax-apple trees were planted in wooden containers with the volumes of $40,90,200,730$, or $1700 \mathrm{~L}$. The design was a randomized complete block with 12 single-tree replications for each container size.

The potting mixture consisted of bark compost, field soil, and peat [1:2:1 (by volume)]. The trees were transplanted to the container on 18 Oct. 1991, grown outdoors, drip irrigated, and fertilized with $0.2 \%$ solution of Hyponex No. 2 (Hyponex Co., Copley, Ohio) $(20 \% \mathrm{~N}-$ $20 \% \mathrm{P}_{2} \mathrm{O}_{5}-20 \% \mathrm{~K}_{2} \mathrm{O}$ ) to maintain tree growth. The trees were left unpruned after planting. Soil temperature and water potential were measured to ensure that excessive root temperatures or water stress did not occur. The plant height, canopy width, and trunk diameter $15 \mathrm{~cm}$ aboveground were recorded at 2month intervals starting 1 Feb. 1992. Trunk cross-sectional area (TCSA) was calculated from trunk diameter. TCSA increase also was calculated. During harvest, fruit were counted and weighed and total fruit fresh mass per tree was calculated as yield. The yield efficiency was calculated from dividing the yield by the TCSA at 18 months after planting.

At the end of the first and second year, three trees in each treatment were analyzed for shoot and root biomass. Leaf area and count were recorded, and all leaves, shoots, and roots were washed and oven-dried at $70^{\circ} \mathrm{C}$ for total plant dry mass analysis.

All criteria of growth and fruiting, except shoot : root ratio, were analyzed by regression analysis using container volumes as the independent variable.

\section{Results and Discussion}

Twenty-two months after planting, plant height had increased $\approx 120 \%$ for plants grown in 90-, 200-, 730-, or 1700-L containers (LCT), whereas plant height increased only $70 \%$ in the 40 LCT (Table 1). There consistently was a significant correlation between plant height and container volumes at each sampling time, but the coefficients of determination $\left(r^{2}\right)$ were

Table 1. Effect of container volume on the plant height of wax-apple trees.

\begin{tabular}{|c|c|c|c|c|c|c|c|}
\hline \multirow{3}{*}{$\begin{array}{l}\text { Container } \\
\text { vol (liters) }\end{array}$} & \multicolumn{7}{|c|}{ Plant ht $(\mathrm{cm})$} \\
\hline & \multicolumn{7}{|c|}{ Months after planting } \\
\hline & 3.5 & 6 & 8 & 11 & 14 & 18 & 22 \\
\hline 40 & 97 & 103 & 109 & 121 & 131 & 160 & 167 \\
\hline 90 & 104 & 113 & 121 & 157 & 172 & 191 & 222 \\
\hline 200 & 113 & 124 & 138 & 176 & 188 & 215 & 248 \\
\hline 730 & 117 & 122 & 159 & 202 & 218 & 238 & 261 \\
\hline 1700 & 111 & 130 & 167 & 196 & 216 & 228 & 260 \\
\hline \multicolumn{8}{|l|}{ Significance $^{z}$} \\
\hline Linear & 0.06 & $0.31^{* *}$ & $0.56^{* *}$ & $0.38^{* *}$ & $0.74^{* *}$ & $0.30^{* * *}$ & $0.30^{* *}$ \\
\hline Quadratic & $0.20^{*}$ & $0.37^{* *}$ & $0.70^{\text {** }}$ & $0.64^{* *}$ & $0.66^{* *}$ & $0.57^{* *}$ & $0.50^{* *}$ \\
\hline
\end{tabular}


relatively low at 3.5 and 6 months of planting. The increase in canopy width after 22 months was $230 \%, 158 \%, 145 \%, 130 \%$, and $110 \%$ in $1700,730,200,90$, and 40 LCT, respectively (Table 2). In general, plants in 40 LCT had the smallest canopy, and the canopy width was positively related to container volume 6 months after planting. For 730 and 1700 LCT, differences in canopy width became evident 22 months after planting, while their plant heights remained similar throughout the 22-month growing period.

TCSA has been used to evaluate the quantity of vegetative growth in various fruit crops (Ferree and Rhodus, 1993; Layne et al., 1994; Zimmerman, 1991). The increase in TCSA during the 22-month experiment revealed no significant differences $(P<0.05)$ among treatments in the first 3.5 months, but the increase in TCSA was quadratically related to container volume $(P<0.05)$ after 6 months (Fig. 1). Twenty-two months after planting, ratios of TCSA increase between the 40 and those of 90, 200, 730, and 1700 LCT were 1, 1.4, 1.6, 2, and 2.6, respectively. Nevertheless, Richards (1986) also reported that there were no significant trunk diameter differences among treatments of peach trees planted in one of four containers, with volumes ranging from 0.5 to $3 \mathrm{~m}^{3}$ until the end of the third year. Wax-apple trees produce five to six flushes a year and accumulate much structural and storage materials (Shu et al., 1990), whereas peach, a deciduous fruit tree with a limited growing season, took longer than wax-apple to exhibit its limitation on growth in terms of differences in trunk diameter. Species may also respond differently to restricted container volume.

At the end of the first-year's growth, leaf count, leaf area, leaf dry mass, stem dry mass, shoot dry mass, and root dry mass increased linearly with increased container volume (Fig. $2)$. At the end of the second-year's growth, each biomass component had increased substantially over that of the first year (Fig. 2). Although all treatments had a lower shoot : root ratio in the second year, it remained between 3.9 and 4.5 at the end of the firstyear's growth, and between 2.8 and 3.3 in the second year, with no significant differences among treatments (Fig. 3).

There are several reports concerning the interrelationship between shoot and root development of fruit trees (Bevington and Castle, 1985; Head, 1968, 1969; Kramer and Kozlowski, 1979; Williamson and Coston, 1989). According to Kramer and Kozlowski (1979), a woody plant has a characteristic shoot : root ratio that remains constant in a stable environment. Plants could reestablish their shoot : root ratio after being root pruned (Geisler and Ferree, 1984a). Richards and Rowe (1977a) also reported that root restriction could result in limited shoot growth, but that the shoot : root ratio was unaltered. Our results indicated that container volume could affect the reciprocal balance between shoot and root of wax-apple trees. The results agree well with the observation of apple (Malus domestica Borkh.) trees, which have a tendency to lower their shoot: root ratio as the tree

Table 2. Effect of container volume on the canopy width of wax-apple trees.

\begin{tabular}{|c|c|c|c|c|c|c|c|}
\hline \multirow{3}{*}{$\begin{array}{l}\text { Container } \\
\text { vol (liters) }\end{array}$} & \multicolumn{7}{|c|}{ Plant ht $(\mathrm{cm})$} \\
\hline & \multicolumn{7}{|c|}{ Months after planting } \\
\hline & 3.5 & 6 & 8 & 11 & 14 & 18 & 22 \\
\hline \multicolumn{8}{|c|}{$\mathrm{cm}$} \\
\hline 40 & 82 & 88 & 93 & 135 & 140 & 156 & 175 \\
\hline 90 & 88 & 104 & 116 & 150 & 158 & 192 & 211 \\
\hline 200 & 90 & 108 & 142 & 172 & 191 & 203 & 220 \\
\hline 730 & 91 & 119 & 180 & 212 & 217 & 235 & 244 \\
\hline 1700 & 82 & 101 & 167 & 219 & 233 & 242 & 271 \\
\hline \multicolumn{8}{|l|}{ Significance ${ }^{2}$} \\
\hline Linear & 0.02 & 0.02 & $0.46^{* *}$ & $0.61^{* *}$ & $0.67^{* *}$ & $0.56^{* *}$ & $0.66^{* *}$ \\
\hline Quadratic & 0.11 & $0.36^{* *}$ & $0.83^{* *}$ & $0.79^{* *}$ & $0.82^{* *}$ & $0.73^{* *}$ & $0.72^{* *}$ \\
\hline
\end{tabular}

${ }^{\mathrm{z}}$ Coefficient of determination $\left(r^{2}\right)$ and significance at $P \leq 0.05(*)$ and $0.01(* *)$ for the linear and quadratic terms.
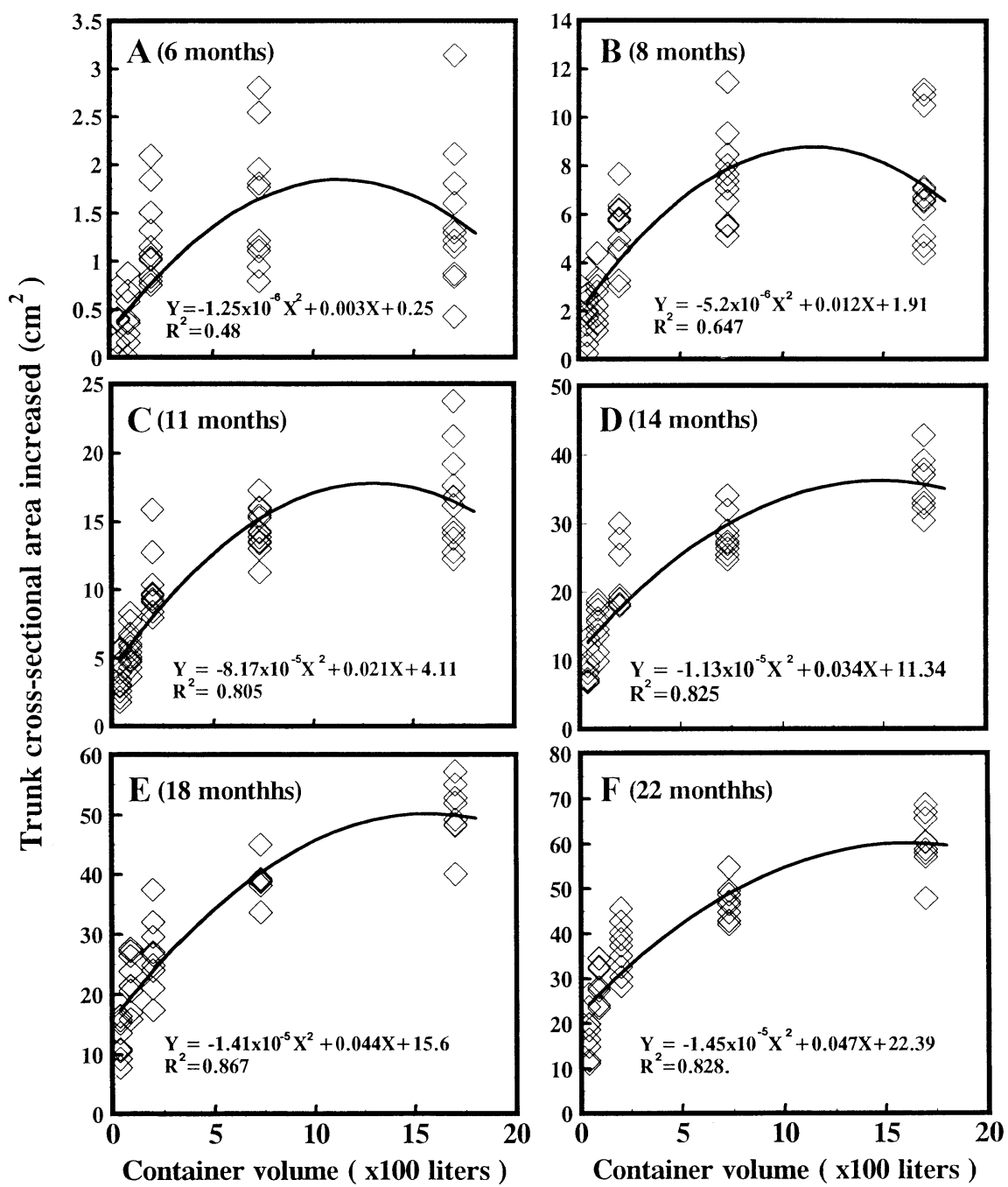

Fig. 1. Relationship between the container volume and trunk cross-sectional areas (TCSA) increase of waxapple trees (A) 6, (B) 8, (C) 11, (D) 14, (E) 18, and (F) 22 months after planting.

ages by allocating more resources to the root system (Avery, 1970).

Eighteen months after planting, the first crop of wax-apple fruit was harvested (April through June, 1992). Trees in the 730 LTC had the highest yield followed by trees in the 1700 , 200, 90, and 40 LTC (Fig. 4). Yield efficiency (yield/TCSA) of the 730 LTC was highest value among all treatments (Fig 4).

Richards (1986) reported that root restriction did not affect fruit size of peaches grown in various soil volumes, but yields were lower for those grown in smaller containers. Williamson and Coston (1990) found that peach trees planted in fabric-lined trenches to limit root distribution had smaller canopies, but had more flowers per node and higher yields than trees planted in conventional or other planting methods. In our study, yield and yield efficiency of trees in 730 LTC did not differ from those in $1700 \mathrm{LTC}$. We assumed that the roots in the larger container did not explore the entire soil mass and, therefore, grew more vegetatively, which, in turn, reduced repro- 

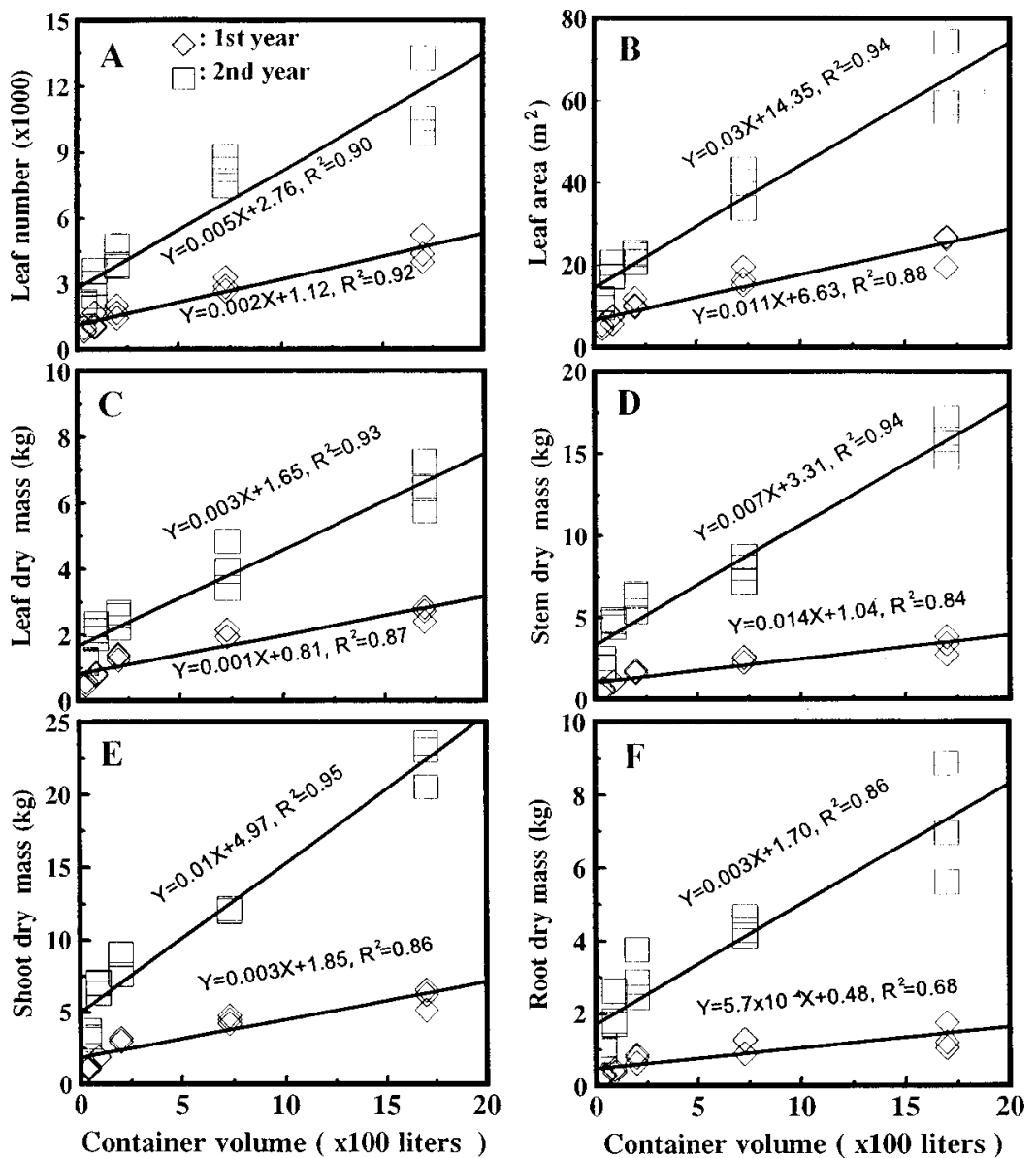

Fig. 2. Relationship between the container volume and (A) leaf number, (B) leaf area, (C) leaf dry mass, (D) stem dry mass, $(\mathbf{E})$ shoot dry mass, $(\mathbf{F})$ root dry mass of wax-apple trees.

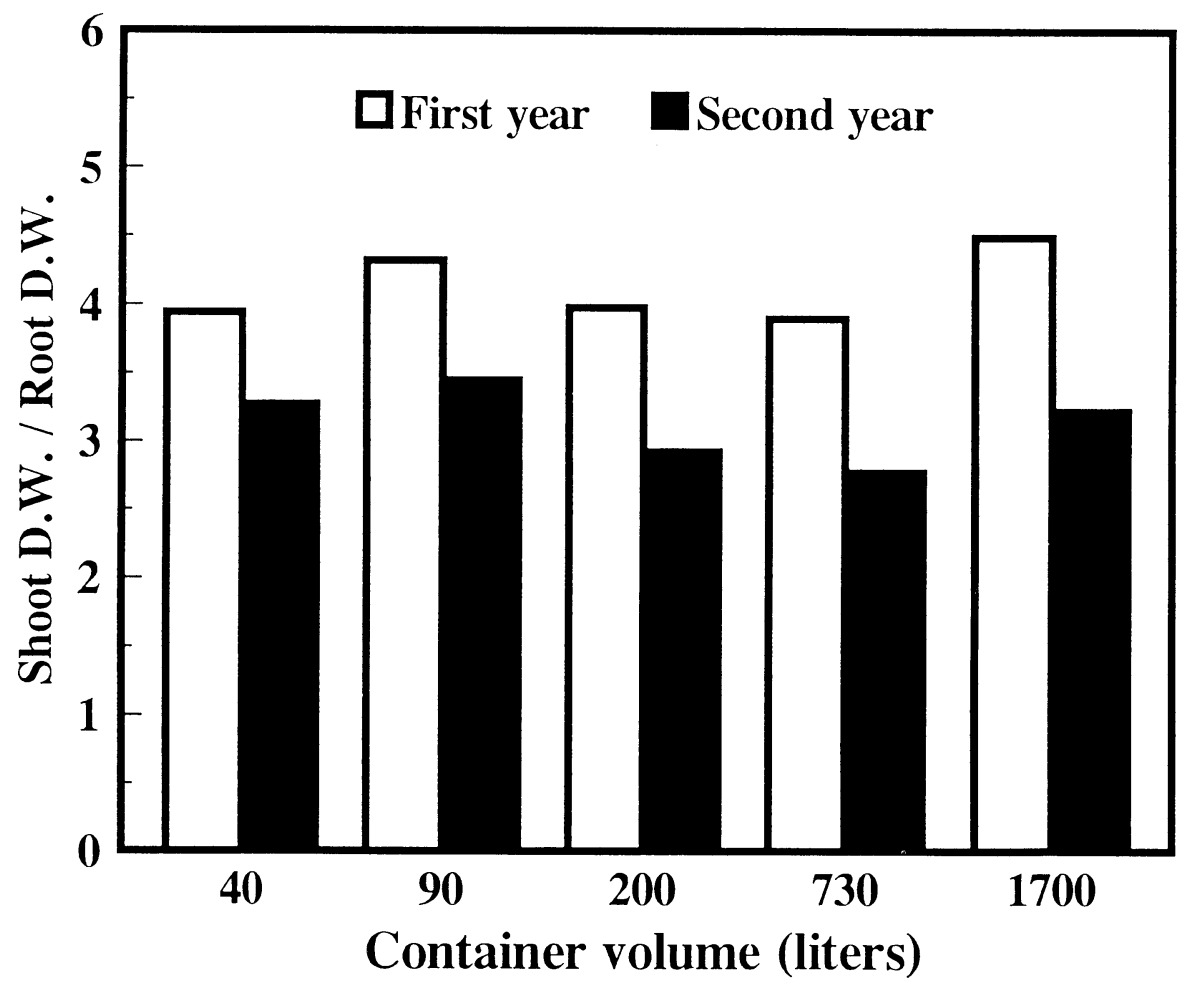

Fig. 3. Effect of container volume on the shoot : root ratio (dry basis) of wax-apple trees planted in various volumes of soil. ductive growth. To test this assumption, data would need to be collected over several years to learn when root restriction occurs in the largest containers.

The effect of root restriction on vegetative growth of wax-apple trees has been confirmed. Whether the growth substances produced by the root system play a similar role in the waxapple tree as in peach trees (Richards and Rowe, 1977a, 1977b) merits further investigation.

\section{Literature Cited}

Avery, D.J. 1970. Effects of fruiting on the growth of apple trees on four rootstock varieties. New Phytol. 69:19-30.

Bevington, K.B. and W.S. Castle. 1985. Annual root growth pattern of young citrus trees in relation to shoot growth, soil temperature, and soil water content. J. Amer. Soc. Hort. Sci. 110:840-845.

Carmi, A. and B. Heuer. 1981. The role of roots in control of bean shoot growth. Ann. Bot. 48:519 527.

Ferhandez-Escobar, R.M., P. Lopez-Rivares, and M. Pazsuarez. 1987. Girdling as a means of increasing fruit size and earliness in peach and nectarine cultivars. J. Hort. Sci. 62:463-468.

Ferree, D.C. and W.T. Rhodus. 1993. Apple tree performance with mechanical hedging or root pruning in intensive orchards. J. Amer. Soc. Hort. Sci. 118:707-713.

Geisler, D. and D.C. Ferree. 1984a. Response of plants to root pruning. Hort. Rev. 6:155-188.

Geisler, D. and D.C. Ferree. 1984b. The influence of root pruning on water relations, net photosynthesis, and growth of young 'Golden Delicious' apple tress. J. Amer. Soc. Hort. Sci. 109:827837.

Head, G.C. 1968. Seasonal changes in the diameter of secondarily thickened roots of fruit trees in relation to growth of other parts of the tree. J. Hort. Sci. 43:275-282.

Head, G.C. 1969. The effects of fruiting and defoliation on seasonal trends in new root production on apple trees. J. Hort. Sci. 44:175-181.

Kramer, P.J. and T.T. Kozlowski. 1979. Physiology of woody plants. Academic, New York. p. 590591.

Layne, R.E.C., C.S. Tan, and D.M. Hunter. 1994. Cultivar, ground-cover, and irrigation treatments and their interactions affect long-term performance of peach trees. J. Amer. Soc. Hort. Sci. 119:12-19.

Lin, H.S., L.R. Chang, J.H. Lin, W.J. Liaw, and C.H. Lin. 1983. The application of cyanamide on termination of dormancy in grapevine bud (II) Field test. PNSC (ROC) 7:237-242.

Lin, H.S., C.H. Lin, and G.Y. Jauh. 1989. Enhancement of germination and ethylene production of oriental pear cv. Liauli by application of thidiazuron and cyanamide. Acta Hort. 239:125128.

Proebsting, E.L., P.H. Jerie, and J. Irvine. 1989. Water deficients and rooting volume modify peach tree growth and water relations. J. Amer. Soc. Hort. Sci. 114:368-372.

Richards, D. 1986. Tree growth and productivitythe role of roots. Acta Hort. 175:27-36.

Richards, D. and R.N. Rowe. 1977a. Effects of root restriction, root pruning and 6benzylaminopurine on the growth of peach seedlings. Ann. Bot. 41:729-740.

Richards, D. and R.N. Rowe. 1977b. Root-shoot interactions in peach: The function of the root. Ann. Bot. 41:1211-1216.

Schupp, J.R. and D.C. Ferree. 1987. Effect of root pruning at different stages of growth on growth 

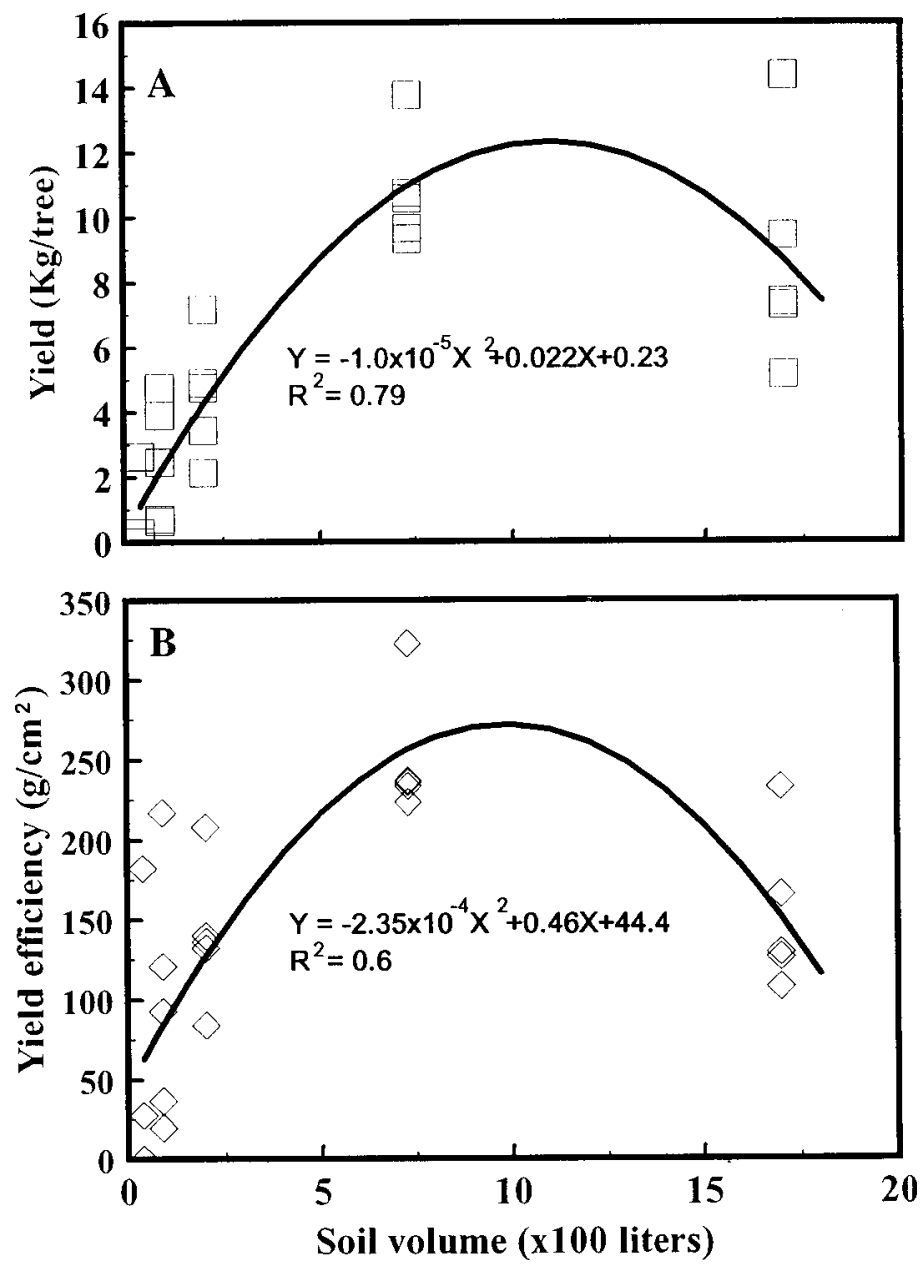

and fruiting of apple trees. HortScience 22:387390.

Schupp, J.R. and D.C. Ferree. 1988. Effects of root pruning at four levels of severity on growth and yield of 'Melrose'/M.26 apple trees. J. Amer. Soc. Hort. Sci. 113:194-198.

Shu, Z.H., D.N. Wang, and T.F. Sheen. 1990. Techniques for producing off season wax-apples, $\mathrm{p}$. 27-37. In: International symposium on off-season production of horticultural crops. Food and Fertilizer Technology Center Book Series No. 41.

Tukey, L.D. 1981. The growth regulator PP-333 on apples. HortScience 16:401-405.

Williamson, J.G. and D.C. Coston. 1989. The relationship among root growth, shoot growth, and fruit growth of peach. J. Amer. Soc. Hort. Sci. 114:180-183.

Williamson, J.G. and D.C. Coston. 1990. Planting method and irrigation rate influence vegetative and reproductive growth of peach planted at high density. J. Amer. Soc. Hort. Sci. 115:207212.

Williamson, J.G., D.C. Coston, and J.A. Cornell. 1992. Root restriction affects shoot development of peach in a high-density orchard. J. Amer. Soc. Hort. Sci. 117:362-367.

Wood, B.W. 1984. Influence of paclobutrazol on selected growth and chemical characteristics of young pecan seedling. HortScience 19:837-839.

Zimmerman, R.H. 1991. Response of micropropagated apple trees to field establishment procedures. HortScience 26:1364-1365.

Fig. 4. Relationship between the container volume and yield (A) and yield efficiency (B) of wax-apple trees. 